\title{
Immediate effects of using ankle-foot orthoses in the kinematics of gait and in the balance reactions in Charcot-Marie-Tooth disease
}

\author{
Efeitos imediatos do uso de órteses tornozelo-pé na cinemática da
} marcha e nas reações de equilíbrio na doença de Charcot-Marie-Tooth

Efectos inmediatos del uso de una ortesis para tobillo-pie en la cinemática de la marcha y en las reacciones de equilibrio en la enfermedad de Charcot-Marie-Tooth

Rouse Barbosa Pereira', Lílian Ramiro Felício', Arthur de Sá Ferreira', Sara Lúcia de Menezes', Marcos Raimundo Gomes de Freitas², Marco Orsini ${ }^{1,2}$

\begin{abstract}
I The Charcot-Marie-Tooth (CMT) disease is a peripheral hereditary neuropathy with progressive distal muscle atrophy and weakness, mainly in lower limbs, that evolves limiting the gait and balance. The objective of the study was to analyse the immediate effects of using Ankle-Foot Orthosis (AFO) in the gait's kinematics and balance in patients with CMT. Nine individuals were evaluated by Tinetti scales and Dynamic Gait Index (DGI) and gait's kinematics parameters through the motion capturing system. These evaluations were done before and during the use of AFO. Two-Way repeated analysis of variance was done to try the main or interaction effects related to "orthoses" and "repetition". A significant interaction effect was observed between the gait cycle and use the AFO to the average velocity (Wilks' Lambda=0.156, $p=0.030, \eta^{2}=0.844$ ) like significant main effects in the ankle joint to the gait cycle (Wilks' Lambda $=0.091, p=0.008$, $\eta^{2}=0.909$ ) and the use of AFO (Wilks' Lambda=0.444, $p=0.013, \eta^{2}=0.556$ ). It was observed a significant change in the DGI scale during the use of AFO $(p<0.05)$. The use of AFO promoted immediate effects on gait kinematics and in balance reactions. The results suggest that the use of AFO is an efficient strategy to stabilize the ankle joint, besides avoiding foot drop in patients with CMT.
\end{abstract}

Keywords I Charcot-Marie-Tooth Disease; Orthotic Devices; Gait; Postural Balance.
RESUMO I A doença de Charcot-Marie-Tooth (CMT) é uma neuropatia periférica hereditária caracterizada por atrofia e paresia progressiva da musculatura distal, principalmente em membros inferiores, que evolui com limitações na marcha e no equilibrio. O objetivo do estudo foi analisar os efeitos imediatos do uso de ÓrteseTornozelo-Pé (OTP) na cinemática da marcha e no equilibrio de pacientes com CMT. Nove indivíduos foram avaliados pelas escalas de Tinetti e DynamicGait Index (DGI) e os parâmetros cinemáticos da marcha através de cinemetria. As avaliações foram realizadas antes e durante o uso das órteses. A análise de variância com medidas repetidas foi realizada para testar o efeito principal e de interação dos fatores "órtese" e "repetição". Foi observado um efeito de interação significativo entre o ciclo da marcha e o uso da OTP para a média da velocidade (Wilks' Lambda=0,156, p=0,030, $\eta^{2}=0,844$ ), assim como efeito principal significante na articulação do tornozelo para o ciclo da marcha (Wilks' Lambda=0,091, p=0,008, $\eta^{2}=0,909$ ) e para o uso da OTP (Wilks' Lambda=0,444, $\mathrm{p}=0,013, \eta^{2}=0,556$ ). Foi observada uma modificação significativa na escala DGI durante o uso da OTP ( $p<0,05)$. O uso de OTP promoveu efeitos imediatos na cinemática da marcha e nas reações de equilibrio. Os resultados obtidos sugerem que o uso de OTP é uma estratégia eficaz na estabilização do tornozelo, além de evitar o derreamento do pé em pacientes com CMT.

Descritores I Doença de Charcot-Marie-Tooth; Aparelhos Ortopédicos; Marcha; Equilíbrio Postural.

Study conducted in the Graduate Program in Rehabilitation Sciences at Centro Universitário Augusto Motta (UNISUAM) - Bonsucesso (RJ), Brazil.

'Graduate Program in Rehabilitation Sciences at UNISUAM - Bonsucesso (RJ), Brazil.

¿Universidade Federal Fluminense (UFF) - Niterói (RJ), Brazil. 
RESUMEN I La enfermedad de Charcot-Marie-Tooth (CMT) es una neuropatía periférica hereditaria caracterizada por atrofia y paresia progresiva de la musculatura distal, principalmente en los miembros inferiores, que evoluciona con limitaciones en la marcha y en el balance. El objetivo de esto estudio fue analizar los efectos inmediatos del uso de ortesis para tobillo-pie (OTP) en la cinemática de la marcha y en el balance de pacientes con CMT. Nueve sujetos fueron evaluados por las escalas de Tinetti y DynamicGait Index (DGI) y los parámetros cinemáticos de la marcha por la cinemetria. Las evaluaciones fueron realizadas antes y durante el uso de la ortesis. El análisis de variancia con medidas repetidas fue realizado para testar el principal efecto y de interacción de los factores "ortesis" y “repetición”. Se observó un efecto de interacción significativo entre el ciclo de la marcha y el uso de OTP para la media de velocidad (Wilks' Lambda=0,156, p=0,030, $\eta^{2}=0,844$ ), como también el principal efecto significativo en la articulación del tobillo para el ciclo de la marcha (Wilks' Lambda=0,091, p=0,008, $\eta^{2}=0,909$ ) y para el uso de una OTP (Wilks' Lambda=0,444, p=0,013, $\eta^{2}=0,556$ ). Se observó una modificación significativa en la escala DGI durante el uso de una OTP $(p<0,05)$. El uso de una OTP promovió efectos inmediatos en la cinemática de la marcha y en las reacciones de balance. Los resultados obtenidos sugieren que el uso de OTP es una eficaz estrategia para estabilizar el tobillo, y evita la curvatura del pie en pacientes con la CMT.

Palabras clave I Enfermedad de Charcot-Marie-Tooth; Aparatos Ortopédicos; Marcha; Balance Postural

\section{INTRODUCTION}

The Charchot-Marie-Tooth disease (CMT) is the most frequent type among hereditary neuromuscular disorders. It can be classified as demyelinating (CMT1) and axonal (CMT2). Other classifications are based on transmission patterns and genetic pool. With a slow and progressive evolution, it is characterized by amyotrophy, paresis, superficial and profound hypoesthesia, and distal hypo- or areflexia ${ }^{1,2}$. In the lower limbs, it affects especially the muscles of the distal third, causing functional impairments during gait and balance reactions $\mathrm{s}^{3,4}$.

The pattern of gait in individuals with CMT is characterized by foot-dragging during the swing phase, with increased compensation of hip and knee flexion. Deficits in plantar flexion are also observable, in addition to a decrease in the length and width of steps, increased base of support, and steppage gait ${ }^{5,6}$.

Rehabilitation resources have been proposed with the purpose of improving gait ${ }^{6,7}$, in special the use of AnkleFoot Orthoses $(\mathrm{AFO})^{8}$. AFOs are commonly prescribed for musculoskeletal disorders of the ankle and/or subtalar joints for the purposes of stabilizing knee joints during the swing phase and avoiding plantar flexion during the initial contact phase ${ }^{9,10}$. Although the adherence to this device is still low among patients with CMT, its prescription seems relevant, as it promotes improved balance reactions and gait performance in this population ${ }^{11-15}$.

Kinematic analyses of gait have been considered determinant for the conduction of therapy treatments and the prescription of orthoses, as well as for pre- and post-treatment assessments ${ }^{16}$. These analyses enable the identification of biomechanical damage caused by muscle weakness, along with proprioceptive deficits and their repercussion on the functional aspects of gait and balance reactions in individuals with $\mathrm{CMT}^{17}$. The Tinetti scale and the Dynamic Gait Index (DGI) are also applicable to the scientific-clinical context, as they are imbued with psychometric characteristics that are easily handled, low costs and good reliability, and are thus useful in assessing balance and mobility, in addition to predicting the risk of falls ${ }^{18-21}$.

The choice for this rehabilitation modality applying AFOs to the lower limbs - is based on the evidence of some scientific studies in which gait was analyzed among individuals with CMT and an association was found between the use of $\mathrm{AFO}$ and improvements in gait and repercussions concerning balance and protection reactions ${ }^{10-14}$. However, up until the present moment, we have not found any scientific studies by authors who investigated the immediate effects of AFOs on gait and their implications in the risk of falling and postural instability in individuals with CMT, which is the proposal of the present study.

By investigating the immediate effects of AFOs among patients with CMT, we aim at stimulating the use of this device in this population, where adherence is still very low. From a clinical perspective, patients with CMT who use AFOs usually experience the disease more severely, as the physical and psychological discomfort caused by this device lead many patients to abandon treatment ${ }^{11,13,15}$. Furthermore, rehabilitating patients with CMT by means of using AFOs can lower costs in public health, since CMT is a chronic, progressive and incurable disease ${ }^{8}$. In the Unified Health System, orthoses and other orthopedic devices are good intervention options, due to the low costs incurred in their production and because they contribute in cutting down rehabilitation expenses, in addition to reducing the potential future demand for other health services ${ }^{22}$. 
We believe that the use of AFOs reduces excessive hip/knee flexion during the swing phase as well as postural instability. It also minimizes alterations found in variables of gait, such as decreases in the length and speed of steps and increases in the duration of steps in patients with CMT.

\section{METHODOLOGY}

This is a quasi-experimental study conducted with a convenience sample that counted 10 patients diagnosed with CMT who sought the neurology department at the Antônio Pedro University Hospital of Universidade Federal Fluminense (HUAP/UFF) between July 2012 and April 2013. The inclusion criteria were: being diagnosed with CMT; age range between 18 and 60 years; and having a referral for AFO use. The exclusion criteria were: presence of pain, joint blockages or impairments caused by orthopedic surgery in the lower limbs; AFO use in the last six months prior to the study; clinical conditions (diabetes or severe heart problems) that affected independent mobility; and other neurological diseases that interfered with gait and/or balance. One of the patients was excluded from the study for experiencing pain in the lower limbs during the assessment with AFO. Therefore, 9 individuals $(n=9)$ participated in the study, 4 men and 5 women, with an age average of 41 years (SD 11), average body mass of $71 \mathrm{~kg}$ (SD 14) and average height of $1.64 \mathrm{~m}$ (SD 0.07).

We complied with Resolution 196/96 of the National Health Council, and the research study was approved by the Ethics Committees of Centro Universitário Augusto Motta (UNISUAM) (report number 119.818) and of HUAP/UFF (report number 118.488).

\section{Instruments}

\section{Kinematic gait data: kinematics}

We used Qualisys Track Manager (QTM) 1.6.0.x, a movement analysis system with an acquisition frequency of $240 \mathrm{~Hz}$, imbued with three interconnected Proreflex infrared cameras. The data were captured and processed by the software QTM.

\section{Balance: Tinetti Gait and Balance Assessment Tool}

The Tinetti Scale was translated and culturally adapted to Brazil by Gomes, with formal evidence of its validity and reliability ${ }^{18}$. This scale assesses balance and gait with scores that vary from 0 to 28 points, in which a score lower than 19, and between 19 and 24 points represent, respectively, high and moderate risks of falls ${ }^{19}$.

\section{Qualitative gait data: Dynamic Gait Index}

The DGI is a reliable tool used to assess human gait and balance that was translated and culturally adapted to the Portuguese language by Castro et al. ${ }^{20}$. It is composed of eight tasks that involve gait in different sensory contexts. Its score varies from 0 to 24 points, in which 19 or less points indicate a high risk of falls ${ }^{21}$.

\section{Muscle function: the Medical Research Council}

The individuals' muscle function was assessed through the instrument devised by the Medical Research Council (MRC), which is composed of scores that vary from 0 to 5 points for each muscle group tested. Its advantage is that it is a test of quick application and a simple way to assess muscle function. Moreover, it is costfree and does not require any equipment to be applied ${ }^{23}$.

\section{Procedures}

Anamneses and neurological examinations were conducted to characterize the participants' clinical condition. In the neurological examination, their muscle function was assessed through the MRC instrument, followed by evaluations of their superficial and profound sensibility, as well as profound reflexes. Next, we carried out the assessment of gait and balance reactions using the Tinetti and the DGI scales ${ }^{18,20}$, followed by a kinematic assessment of gait using the QTM system. Firstly, the participants underwent the assessments wearing their habitual shoes, and after a ten-minute break, they used an AFO along with their regular shoes. All assessments were conducted at the Laboratory for Analysis of Human Movement of UNISUAM.

In the kinematic analysis, only the dominant lower limb was assessed due to the CMT's symmetric pattern ${ }^{3}$. We used seven $15-\mathrm{mm}$ reflexive and passive markers attached to the participants' skin with a double-sided tape on the following anatomic spots: posterior superior iliac spine, anterior superior iliac spine, greater trochanter, lateral epicondyle, lateral malleolus, $5^{\text {th }}$ metatarsal, and posterior facet of the calcaneus ${ }^{16}$. The participants were instructed to walk at their habitual speed on a surface that was three meters long by one meter wide, without 
using an AFO at first. All of them repeated this task five times. Next, the orthoses were attached and the five repetitions were performed once again with the AFOs. The variables analyzed were speed, displacement and duration of steps, and angular displacement of the hip, knee and ankle on the sagittal plane. To collect data, the axes and reference coordinates were defined as follows: axis X (lateral-medial), axis Y (anterior-posterior) and axis $Z$ (superior).

\section{STATISTICAL ANALYSIS}

The data were analyzed through the software SPSS (version 17 for Windows). The level of significance adopted was $p<0.05$. The descriptive analysis is presented here in bar graphs and tables, considering the mean $\pm \mathrm{SD}$ for the continuous variables, and median values (minimum; maximum) for the categorical variables. The association between the variables [age, weight, height, Tinetti index, DGI, speed of step (m/s), Movement Amplitude (MA) of the hip (degrees), knee MA (degrees) and ankle MA (degrees)] was tested through Spearman's Correlation Coefficient and is displayed on a table. For the comparative analysis, we used the general linear model with repeated measurements for the factors orthosis (without; with) and repetition (1, 2, 3, 4 and 5) for each dependent variable [stepping speed $(\mathrm{m} / \mathrm{s})$, hip MA (degrees), knee MA (degrees) and ankle MA (degrees)], as well as the Wilcoxon Signed Rank test for the variables Tinetti index and DGI.

\section{RESULTS}

In regards to sensitivity, all individuals presented alterations in their superficial and profound sensitivity in the distal crural third, varying according to the degree of compromise (anesthesia or hypoesthesia). Profound reflexes in the lower limbs were either null or bilaterally decreased in the entire sample. Crural distal paresis, especially in the dorsal and flexor groupings, was present in all patients assessed. According to the MRC instrument, three individuals were at degree three, three at degree two, two at degree one, and only one individual was at degree zero in regards to the dorsiflexor muscles.

Upon analyzing the sample according to the Tinetti and DGI scales with and without the use of AFO, we observed that the DGI presented significant modifications between the two conditions $(p=0.048)$. While using the AFO, the participants performed $8.4 \%$ better when compared to not using orthoses (Table 1).

The main results concerning the linear and angular data of gait with and without AFO are summarized on Table 1 and Graph 1. A significant difference can be observed in the median of stepping speed, which was $25 \%$ lower without the use of AFO. We observed a significant interaction effect between the cycle of gait and the use of AFO on speed average (Wilks' Lambda $\left.=0.156, p=0.030, \eta^{2}=0.844\right)$, as well as a main effect pertaining to the cycle (Wilks' Lambda $=0.144$, $\mathrm{p}=0.014, \eta^{2}=0.886$ ) and to the use of AFO (Wilks' Lambda $\left.=0.496, p=0.022, \eta^{2}=0.504\right)$. As for hip MA, we did not observe any significant main effects regarding gait cycle (Wilks' Lambda $=0.369, p=0.214, \eta^{2}=0.631$ ) and AFO use (Wilks' Lambda $=0.956, p=0.560$, $\eta^{2}=0.044$ ), and did not detect any significant interaction effect between these two factors (Wilks' Lambda $=0.544$, $\left.p=0.466, \eta^{2}=0.456\right)$. In regards to knee MA, we did not observe any significant main effects regarding gait cycle (Wilks' Lambda $=0.325, p=0.162, \eta^{2}=0.675$ ) and AFO use (Wilks' Lambda=1.000, p=0.986, $\eta^{2}=0.000$ ), with no interaction effect between them (Wilks' Lambda $\left.=0.309, p=0.144, \eta^{2}=0.691\right)$. Concerning ankle MA, we observed a significant main effect on gait cycle (Wilks' Lambda=0.091, p=0.008, $\eta^{2}=0.909$ ) and AFO use (Wilks' Lambda=0.444, $\mathrm{p}=0.013, \eta^{2}=0.556$ ). However, we did not observe a significant interaction

Table 1. Scores obtained through the Tinetti scale and the Dynamic Gait Index, and kinematic data regarding gait with and without the use of orthosis ( $n=9$ )

\begin{tabular}{|c|c|c|c|c|c|}
\hline \multirow{2}{*}{ Parameter } & \multicolumn{2}{|c|}{ Without orthosis } & \multicolumn{2}{|c|}{ With orthosis } & \multirow{2}{*}{$\mathrm{p}$-value } \\
\hline & Mean \pm SD & Median & Mean \pm SD & Median & \\
\hline Tinetti & $22 \pm 4$ & $23(15-27)^{*}$ & $23 \pm 3$ & $23(19-27)$ & 0.157 \\
\hline Dynamic Gait Index & $16 \pm 4$ & $17(11-20)$ & $18 \pm 4$ & $17(13-23)$ & 0.048 \\
\hline Stepping speed $(\mathrm{m} / \mathrm{s})$ & $0.97 \pm 0.02$ & $0.98(0.93-0.98)$ & $0.73 \pm 0.08$ & $0.76(0.63-0.80)$ & 0.022 \\
\hline Hip amplitude (degrees) & $28 \pm 1.2$ & $27(27-30)$ & $26 \pm 1.4$ & $29(25-29)$ & 0.560 \\
\hline Knee amplitude (degrees) & $36 \pm 0.5$ & $36(36-37)$ & $35 \pm 1.6$ & $36(32-36)$ & 0.986 \\
\hline Ankle amplitude (degrees) & $41 \pm 3.4$ & $40(38-47)$ & $19 \pm 0.6$ & 19 (18-19) & 0.013 \\
\hline
\end{tabular}

p<0.05; (*minimum and maximum value, respectively; SD: standard deviation 
effect between the cycle of gait and the use of AFO for this joint (Wilks' Lambda=0.227, $\mathrm{p}=0.072, \eta^{2}=0.773$ ).

We observed a significant correlation concerning AFO use between the following variables: knee MA and ankle MA ( $r=0.733 ; p=0.025)$, hip MA and knee MA ( $r=0.783 ; p=0.013)$, and Tinetti and DGI ( $r=0.802$; $\mathrm{p}=0.009)$. When an AFO was not used, we observed significant correlations between the following variables: Tinetti and DGI ( $r=0.698 ; \mathrm{p}=0.036)$, Tinetti and speed $(r=0.751 ; p=0.020)$, DGI and speed $(r=0.751 ; p=0.020)$, speed and ankle MA ( $r=0.745 ; p=0.021)$, speed and hip MA ( $\mathrm{r}=0.762 ; \mathrm{p}=0.017)$; and hip MA and ankle MA $(r=0.933 ; p<0.001)($ Table 2$)$.

\section{DISCUSSION}

The alterations observed in the individuals' muscle function along with alterations in sensitivity contributed to the presence of biomechanical alterations perceived during the kinematic analysis of gait ${ }^{4}$. In this study, we were able to identify - through kinematic analysis immediate modifications in the linear and angular data concerning gait with the use of $\mathrm{AFO}$, which confirms
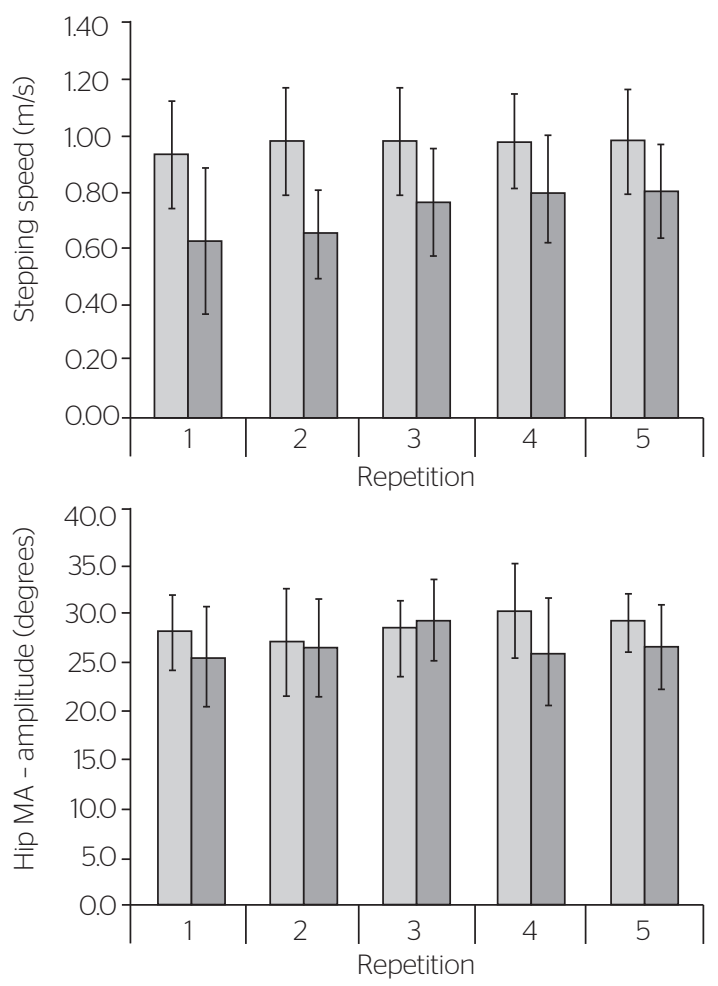

the results found by other researchers ${ }^{17}$. The authors in question analyzed the gait of 16 individuals with CMT, in addition to their clinical characteristics, and concluded that kinematics analyses are useful tools to define the characteristics of gait in individuals with CMT.

In regards to the DGI scale, the results showed that the use of AFOs promoted modifications in the performance of gait patterns and balance reactions by all individuals included in the sample, but it was unable to diminish the risk of falls ${ }^{20,21}$.

The hypothesis that the use of AFOs would reduce excessive hip/knee flexion during the swing phase was not confirmed. We observed a change in the mean of hip/knee MA with the use of AFO, but this modification did not reach the significance level adopted $(p<0.05)$. These results differ from the findings of another study ${ }^{10}$ in which the authors investigated the effects of three AFO types on joint angles during the gait of an individual with CMT, and concluded that the use of AFOs during gait decreased excessive hip and knee flexion during the swing phase. However, the data were collected after one month of daily use of the orthoses, which allowed the patient to adapt to the devices. In the present study, the effect investigated was immediate and did not allow for a phase of adaptation, which can
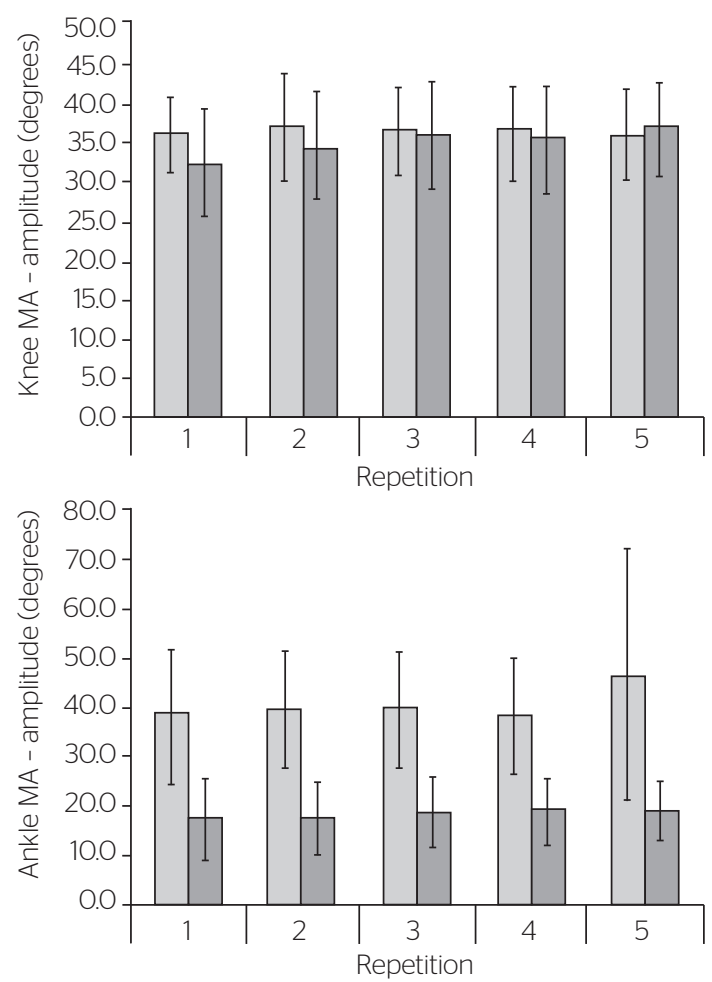

Without orthosis 
Table 2. Spearman's Correlation for age, height, weight, Tinetti scale, Dynamic Gait Index, and kinematic data concerning gait with and without the use of orthoses

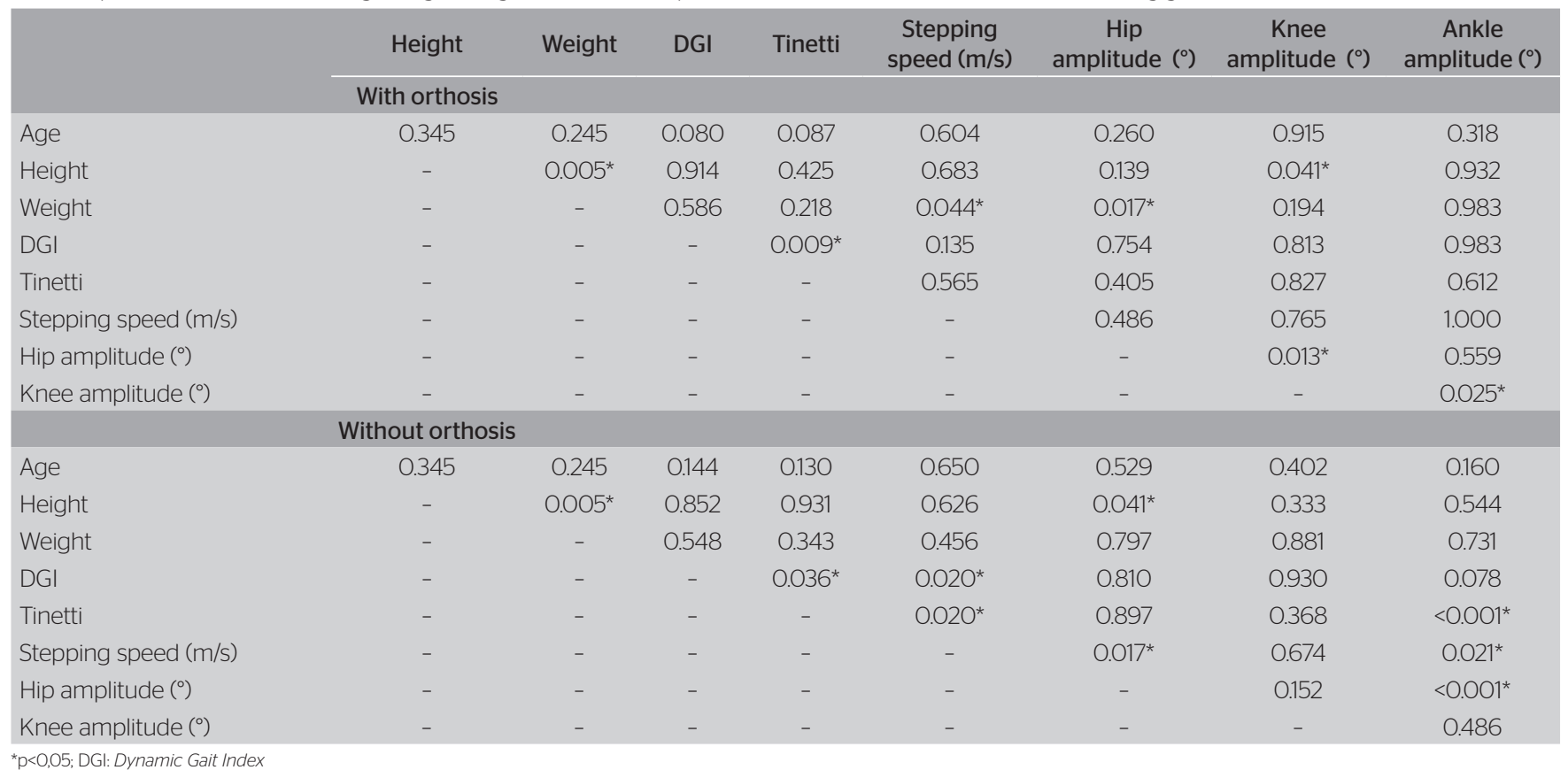

justify the differences in the results. Although it did not improve gait significantly, the use of an AFO modified it immediately. The authors of this study hope that the results will serve as a basis that aids professionals involved with the physical rehabilitation of patients with CMT to stimulate adhesion to this device (still very low in this population).

The AFOs acted by compensating for the muscle weakness of the dorsiflexor grouping during the swing phase and by managing plantar flexion during initial support, thus controlling foot-dragging. These findings are in agreement with those observed by a group of researchers ${ }^{11}$ that reported the case of a patient who presented improvements in the performance of gait patterns, with less inadequate movement synergies after using a type of orthosis developed especially for patients with CMT.

Del Bianco and Fatone ${ }^{12}$ evaluated the functions of a pre-fabricated AFO model made of silicone and another one composed of posterior springs, as well as their effects on the kinematics of the gait of an individual with CMT. The authors reported that both devices improved gait patterns by correcting deviations during the support and swing phase when compared to solely wearing shoes.

The hypothesis that AFOs could minimize alterations found in the linear variables of gait was not confirmed. The AFOs were not capable of immediately minimizing the alterations found in stepping speed, length and duration. These results agree with the findings of other researchers ${ }^{13}$ who characterized the main differences in the clinical presentation and function of the gait of two groups of patients with $\mathrm{CMT}$ (AFO group = regular $\mathrm{AFO}$ use; non- $\mathrm{AFO}$ group). They concluded that the users of AFOs walked more slowly and with more effort. They justified these results with the greater severity of the disease in the AFO group, which leads to a poorer perception of capability during gait performance. In this study, however, we observed that, despite a decrease in speed average, there was an increase in the averages of the DGI and Tinetti scales, which represents functional improvements in the gait of the individuals who participated in our research.

The results of this study demonstrate that the use of AFOs combined with regular shoes modifies the patterns of gait and balance reactions in individuals with CMT, in comparison to wearing only regular shoes. Although the size of the sample is considered respectable, studies with a larger number of individuals and different types of orthoses must be stimulated with the purpose of providing more specific data used to prescribe orthoses to individuals with CMT and stimulating its use within this population. Furthermore, using AFOs to treat patients with CMT can reduce rehabilitation expenses, as low costs are involved in their production. Moreover, they reduce these patients' future demands for Physical Therapy services. 


\section{CONCLUSION}

The use of AFOs promoted immediate changes in gait speed and balance in patients with CMT. However, this device was not capable of immediately minimizing the risk of falls and postural instability in this population. The results obtained suggest that the use of AFOs is an efficient conduct to stabilize ankle joints and manage foot-dragging among patients with CMT. However, it is not possible to extend these conclusions to all individuals with Charcot-Marie-Tooth disease, as the sample studied here was small.

\section{REFERENCES}

1. Vieira THF, Aires RD, Mendonça VA, Correa CL. Reabilitação física em um paciente com a doença de Charcot-Marie-Tooth: relato de caso. Rev Neurociênc. 2009;17(3):287-92.

2. Neves ELA, Kok F. Clinical and neurophysiological investigation of a large family with dominant Charcot-Marie-Tooth type 2 disease with pyramidal signs. Arq Neuropsiquiatr. 2011;69(3):424-30.

3. Fávero RA, Polese JC, Oliveira SG, Schuster RC. Análise da marcha e funcionalidade na doença de Charcot-Marie-Tooth: relato de caso. Rev Neurociênc. 2010;18(1):44-9.

4. Vinci P, Perelli S. Footdrop, foot rotation, and plantarflexor failure in Charcot-Marie-Tooth disease. Arch Phys Med Rehabil. 2002;83(4):513-6.

5. Don R, Serrao M, Vinci P, Ranavolo A, Cacchio A, loppolo F, et al. Foot drop and plantar flexion failure determine different gait strategies in Charcot-Marie-Tooth patients. Clin Biomech (Bristol, Avon). 2007:22(8):905-16

6. Ferrarin M, Bovi G, Rabuffetti M, Mazzoleni P, Montesano A, Moroni I, et al. Reliability of instrumented movement analysis as outcome measure in Charcot-Marie-Tooth disease: results from a multitask locomotor protocol. Gait Posture. 2011;34(1):36-43.

7. Vinci P, Gargiulo P, Panunzi M, Baldini L. Psychological distress in patient with Charcot-Marie-Tooth disease. Eur J Phys Rehabil Med. 2009;45(3):385-9.

8. Pereira RB, Orsini M, Ferreira AS, Silva JG, Corrêa CL, Freitas MRG, et al. Efeitos do uso de órteses na doença de Charcot-Marie-Tooth: atualização da literatura. Fisioter Pesqui. 2012;19(4):388-93.

9. Guillebastre B, Calmels P, Rougier PR. Effects of rigid and dynamic ankle-foot orthoses on normal gait. Foot Ankle Int. 2009;30(1):51-6.
10. Burdett RG, Hassell G. Effects of three types of ankle-foot orthoses on the gait and bicycling of a patient with Chartcot-Marie-Tooth disease. J Prosthet Orthot. 2004:16(1):25-30.

11. Vinci P, Paoloni M, loppolo F, Gargiulo P, Santilli. Gait analysis in patient with severe Charcot-Marie-Tooth disease: a case study with a new orthotic device for footdrop. Eur J Phys Rehabil Med. 2010;46(3):355-61.

12. Del Bianco J, Fatone S. Comparison of silicone and posterior leaf spring ankle-foot orthoses in a subject with Charcot-Marie-Tooth disorder. J Prosthet Orthot. 2008;20(4):155-62.

13. Ramdharry GM, Pollard AJ, Marsden JF, Reilly MM. Comparing gait performance of people with Charcot-Marie-Tooth disease who do and do not wear ankle foot orthoses. Physiother Res Int. 2012:17(4):191-9.

14. Guzian MC, Bensoussan L, Viton JM, Bovis VM, Ramon J, Azulay JP, et al. Orthopaedic shoes improve gait in a Charcot-Marie-Tooth patient: a combined clinical and quantified case study. Prosthet Orthot Int. 2006;30(1):87-96.

15. Vinci P, Gargiulo P. Poor compliance with ankle-foot-orthoses in Charcot-Marie-Tooth disease. Eur J Phys Rehabil Med. 2008;44(1):27-31.

16. Kadaba MP, Ramakrishna HK, Wootten ME. Measurement of lower extremity kinematics during level walking. J Orthop Res. 1990;8(3):383-92.

17. Newman CJ, Walsh M, O'Sullivan R, Jenkinson A, Bennett D, Lynch B, et al. The characteristics of gait in Charcot-Marie-Tooth disease types I and II. Gait Posture. 2007:26(1):120-7.

18. Gomes GC. Tradução, adaptação cultural e exame das propriedades de medida da escala "Performance-oriented mobility assessment" (POMA) para uma amostragem de idosos brasileiros institucionalizados. [dissertação]. Campinas: Universidade Estadual de Campinas; 2003.

19. Karuka AH, Silva JAM, Navega MT. Análise da concordância entre instrumentos de avaliação do equilíbrio corporal em idosos. Rev Bras Fisioter. 2011;15(6):460-6.

20. Castro SM, Perracini MR, Ganança FF. Versão brasileira do Dynamic Gait Index. Rev Bras Otorrinolaringol. 2006;72(6):817-25.

21. Chiu YP, Fritz SL, Light KE, Velozo CA. Use of item response analysis to investigate measurement properties and clinical validity of data for the dynamic gait index. Phys Ther. 2006;86(6):778-87.

22. BRASIL. Ministério da Saúde. Secretaria de Assistência à Saúde. Portaria no 116, de 09 de setembro de 1993. Inclui no Sistema de Informações Ambulatoriais do Sistema Único de Saúde a concessão dos equipamentos de órteses, próteses e bolsas de colostomia. Diário Oficial da União, Brasília, n. 176, 15 set.; 1993.

23. Compston A. Aids to the investigation of peripheral nerve injuries. Medical Research Council: Nerve Injuries Research Committee. His Majesty's Stationery Office: 1942; pp. 48 (iii) ans 74 figures and 7 diagrams; with aids to examination of the peripheral nervous system. By Michael O'Brien for the Guarantors of Brain. Saunders Elsevier: 2010; pp. [8] 64 and 94 figures. Brain. 2010;133(10):2838-44. 